Article

\title{
Reconfiguring Urban Sustainability Transitions, Analysing Multiplicity
}

\author{
Mike Hodson *, Frank W. Geels and Andy McMeekin \\ Sustainable Consumption Institute, University of Manchester, Oxford Rd, Manchester M13 9PL, UK; \\ Frank.Geels@Manchester.ac.uk (F.W.G.); Andrew.Mcmeekin@Manchester.ac.uk (A.M.) \\ * Correspondence: michael.hodson@manchester.ac.uk
}

Academic Editors: Harald Rohracher, Michael Ornetzeder and Philipp Späth Received: 11 November 2016; Accepted: 10 February 2017; Published: 17 February 2017

\begin{abstract}
Cities, and the networked infrastructures that sustain urban life, are seen as crucial sites for creating more sustainable futures. Yet, although there are many plans, the realisation of sustainable urban infrastructures on the ground is uneven. To develop better ways of understanding why this is the case, the paper makes a conceptual contribution by engaging with current understanding of urban sustainability transitions, using urban sustainable mobility as a reference point. It extends these insights to argue that urban transitions are not about technological or social innovation per se, but about how multiple innovations are experimented with, combined and reconfigured in existing urban contexts and how such processes are governed. There are potentially many ways in which urban sustainable mobility can be reconfigured contextually. Innovation is in the particular form of reconfiguration rather than individual technologies. To make analytical sense of this multiplicity, a preliminary framework is developed that offers the potential to think about urban transitions as contextual and reconfigurational. We argue that there is a need to embrace multiplicity and to understand its relationships to forms of reconfiguration, through empirical exploration and further theoretical and conceptual development. The preliminary framework is a contribution to doing so and we set out future directions for research.
\end{abstract}

Keywords: urban; transition; reconfiguration; multiplicity

\section{Introduction}

Cities, and the transport, energy, water and waste infrastructures that sustain urban life, are seen as crucial sites for creating more sustainable futures. Although there are many plans, and a wide range of possible infrastructural innovations, the realisation of sustainable urban infrastructures on the ground is uneven. Urban transitions approaches have sought to contribute to our understanding of why this is the case. These approaches have been subject to - and continue to require- theoretical and conceptual development and empirical exploration. This paper contributes to this endeavour and to debates in this area in this journal [1,2].

To do this, we engage with debates between socio-technical sustainability transitions and urban geography. In recent years, dialogue at this interface has produced a broad body of work which has sought to bring together the temporal concerns of transitions approaches with spatial issues addressed in geographically-inspired work [3-9]. Using sustainable mobility as a reference point, we seek to extend and deepen this dialogue through opening up three foundational themes in these debates. First, we shift analysis from national systems, which dominates the socio-technical transitions literature, to a focus on urban context. We do this to be able to begin examining how multiple, selective sustainable mobility innovations (e.g., battery electric vehicles, urban cycling hire schemes, inter-modal ticketing etc.) are experimented with and variably reconfigured in cities [2]. Second, it is necessary to understand the governance and institutional arrangements that shape reconfiguration; but it is important not 
to fall in to the trap of reducing and flattening these governance arrangements to the level of the city [10]. Not only does multi-level governance shape sustainable infrastructural innovation in the city but wider processes of global urbanism provide political-economic conditions of possibility for experimentation [11]. Third, though there are many kinds of infrastructural innovations with the potential to contribute to more sustainable urban mobility which ones (in the plural) are selected and how these come to be combined and configured in relation to existing urban infrastructure systems in the city remains poorly understood. Selectivity is mediated through context-specific governance and institutional arrangements, drawing on contested knowledge of and interpretations of 'sustainability'. This leaves the possibility for weaker and stronger conceptions of 'sustainability' to inform transition.

The danger this poses is that urban transitions become seen as almost limitless possibilities of combining elements (multiple experiments [12], forms of governance [13], conceptions of sustainability [14] and combinations of these). This requires that we focus on the different ways that these elements are being reconfigured in particular urban contexts. We develop a preliminary framework to do this and suggest that it is contextual forms of reconfiguration that are a key focus in understanding urban transitions. We recognise that we must be necessarily selective in illustrating our argument within the parameters of a journal article. This being the case, we set out the need to embrace multiplicity in urban transitions research through selective empirical exploration and suggest further theoretical and conceptual development. Theoretically and conceptually our argument is important in developing an approach to urban sustainability transitions that integrates multiple experiments with innovations, with the multi-level governance of urban contexts and contested conceptions of 'sustainability'.

The paper is structured in five further sections. Section 2 addresses the issue of governing urban transitions to sustainability through engaging with debates between socio-technical transitions and urban geography, highlighting many strengths in these debates and setting out areas for further development. Section 3 summarises the methodological approach of the paper. Section 4 sets out three issues that extend the agenda of researching urban transitions, using examples from sustainable urban mobility. Section 5 sketches out a preliminary analytical framework for analysing variety in forms of reconfiguration in urban transitions. Section 6 present conclusions and sets out future research directions.

\section{Current Understanding of Urban Transitions}

How we understand urban transitions to sustainability and in what ways they can be governed has become a preoccupation of academic debates over the last decade. Central to such debates has been a productive dialogue between socio-technical transitions approaches, particularly the Multi-Level Perspective (MLP), and geographical insights. This has produced a broad church of responses. Here we summarise key themes of this dialogue as a means of identifying trends and 'gaps' and further developing this dialogue.

The MLP understands transitions as multi-decade shifts from one system to another system, focusing usually at the national level. To understand these dynamics, it distinguishes three interrelated analytical concepts: socio-technical landscape, regime and niche $[15,16]$. Socio-technical regimes represent the institutional structuring of tangible socio-technical systems; the intangible rules, shared cognitive routines, regulations and standards which structure but do not determine action [17]. Regimes accrue over time through structuration processes between regime elements and also as a response to exogenous landscape pressures and niche-innovations. Niches are 'protected spaces' where radical innovations are nurtured $[18,19]$. Socio-technical landscapes refer to broader exogenous contexts, which often change slowly (e.g., demographics, macro-ideologies, climate change, macro-economics, material organisation of cities), but can occasionally change quickly (e.g., wars, shocks, economic recession, oil price fluctuations) [20].

The MLP often focuses on singular transitions with one niche-innovation struggling against an incumbent regime. Conventionally, the MLP sees niche-innovations as the seeds of transitions 
(variations) and regime and landscape dynamics as the wider (selection) environment. Transitions thus require alignments between developments at multiple levels. Landscape pressures condition cracks and destabilisation within existing regimes, creating windows of opportunity for niche developments that have developed an internal momentum. Yet, as subsequent work has pointed out the 'specific mechanisms underpinning these interactions prove to be far more complex than early versions of the MLP implied' [21] (p. 443), leading to acknowledgement of different pathways to transition involving various dynamics within and between the levels of analysis [17,22].

A body of work from a geographical perspective has sought to engage with the MLP over the last decade $[5,7,8,23-26]$. Inevitably this has involved selective dialogue between two large fields of study rather than a full integration of the MLP with geographical concerns. Initially geographical engagement came from a concern that spatial and territorial issues were underdeveloped in the MLP [4,27]. Case studies conducted through the MLP usually had a national focus and the spatial context for transition was often de facto national transition. In this view, spatial issues were pre-given, underplayed or ignored. Responding to this 'gap', has produced attempts to bring together in various ways transitions in 'what' (systems) and 'where' (various spatial contexts) over the last decade.

Work has engaged both with how visions for energy transition and climate governance are developed in comparative urban and regional contexts [6] and how urban transitions are accomplished [28]. Accomplishment is underpinned by the idea that scales and spaces of transitions are actively, relationally produced and '[s]pace itself is not a given in this view, but socially defined, reproduced and redefined' [24] (p. 70). What follows from this view for core MLP concepts is that: 'Niche, regime and landscape levels are produced and reproduced by relationships between actors acting across space and time ... being configured and emerging out of interactions between actors situated in structures with different temporal dynamics that are spatially heterogeneous' [24] (p. 76). This requires understanding institutional configurations shaping socio-technical processes in particular territorial spaces. These configurations include institutions embedded in a territorial space and at multiple scales (e.g., global, national) beyond the 'local' [4]. This is important as it opens up the possibility for variety in configuring transition processes between different spatial contexts. It also suggests that regimes may be territorially uneven and that the instantiation of a niche or niches may look very different between territorial contexts as the institutional and social networks embedding them vary.

Geographies of transition require a focus on both the distribution of activity (e.g., mobility, energy, waste-producing, etc.) within a particular space but also geographical interconnections between that space and other spaces [7]. Infrastructural innovations have the potential to reconfigure both within a space and between spaces. The significance of this is that:

Recasting transition as geographical process changes the questions that become important for researchers to ask. Viewed through the lens of time, key questions about transition include the different temporalities of technological and policy innovation, the rates at which particular energy technologies may be mainstreamed, or the evolution of consumption behaviour. By contrast, a geographical perspective on transition foregrounds questions about spatial difference (and the co-existence of multiple transition pathways and possibilities) ... [7] (p. 339).

A key focus of this wider debate about the constitution of space and scale in transitions has been the role of cities in transition processes [5]. Research has examined transitions to more sustainable cities, low carbon cities or cities organised as eco-cities of multiple infrastructure systems [29]. Inevitably, this addresses both transitions in urban form and transitions in infrastructure systems. Attempts to enact urban transitions has seen efforts to engage with 'retrofitting' innovations and systems at the level of a city [30,31] and, alternatively, to build new cities that encompass more ecologically 'sound' transport, energy, water and waste systems [32]. Of particular importance here are the ways in which institutional and social interests are organised through governance processes that seek to shape urban 
transitions [33]. This involves not just territorially-specific institutions and interests but also national and international institutions and networks of interests [34,35].

\subsection{Urban Experimentality and Its Limits}

In recent accounts something of an alternative to neo-institutional inspired analyses has developed in more experimentally focused approaches to urban transitions $[28,36]$. The concern is with knowing how to enact and accomplish urban transitions in conditions of deep uncertainty, which includes a multiplicity of sustainability challenges facing cities, from carbon reduction to resource depletion and from austerity to maintaining social cohesion. Knowing how to respond, in circumstances where the governance capacity to do so is often distributed geographically through multi-scalar and horizontal networks [37], is difficult at the level of strategy (knowing what to do) and practice (knowing how to do it). This has underpinned a focus on experimental process through which configurations of technologies and social interests are assembled, experimented with and learned from in a place. Often mobilisation of the concept of experiments, though, has been loose and unclear [38].

To address this lack of clarity, there have been calls to conceive of experimentation as structured 'laboratory' spaces with a focus on learning through instruments, control and measurement rather than solely focusing on unspecific notions of 'change' [38]. This has led to efforts to create purposive spaces for such activities, often characterised as Urban Living Laboratories [38,39]. This kind of socio-technical experiment is in many ways seen as bounded [40], setting parameters for experimentation in the city as a site for learning.

Understandings of what is meant by urban experiments, though, go beyond a bounded focus and are increasingly becoming seen as a strategy of urban governance [28]. Urban experimentation can be broadened to be understood in terms of three concepts: governance experiments, socio-technical experiments and strategic experiments [28]. The first of these focuses on governance and the actors involved in experimental processes of restructuring the local state in addressing what are seen to be urgent problems, claims to resources, efforts to expand authority or mobilise ideology. The second addresses socio-technical experimentation. This form of experimentation resonates with the concept of a niche in the MLP. There, additionally, remains the issue of how the 'same' generic niche is differentially embedded in a particular place. The third focuses on the accomplishment of experiments through purposive forms of experimentation in urban laboratories. The first two of these forms of experimentation are often implicit in the urban context, whereas the latter is an explicit form of experimentation [28]. It is these two implicit processes of experimentation that we focus on in this paper.

In many ways, the city has, 'arguably, always been experimental' in the ways that urban authorities have regularly 'tested' urban knowledge in processes of attempting to improve the city [41] (p. 429). The bringing together of urban governance experimentation and socio-technical experimentation is about purposively embedding something new in a place-even if that something is well-established elsewhere-and how that contributes to efforts to transform the city. The evaluative element is for researchers, to address the politics of these experimental processes asking: 'on whose behalf do urban experiments seek to make change and to what degree is this change truly transformational?' [41] (p. 430).

The larger point about forms of urban experimentation is that they are shaped by wider global forces and crisis. Response to crisis produces experimentation with governance arrangements.

Researchers have 'called for a sustained empirical analysis of the current global financial-economic crisis as a laboratory for urban governance rationalities' [42] (p. 1081). Wider political-economic crisis dynamics stimulate governance experimentation which, when instantiated in particular places, shapes differentiated urban responses to transform place. This view sees crisis as the 'laboratory' where new governance rationalities are experimented with. The effects of this are under-researched but this has fundamental implications for the conditions under which urban experimentation proceeds: 'As we start to see a variety of urban responses unfold across the world, we must ask whether they 
serve to reinforce ongoing neoliberal urban restructuring or effectively produce new, post-neoliberal, urban governance rationalities' [42] (p. 1076). Furthermore, crisis may refer not only to economic and financial crisis but also how environmental and social 'crises' shape governance experimentation.

This discussion speaks to a still unresolved problem as to how we conceive of urban experimentation. If the urban is constituted not just through place-based social interests but through social interests operating beyond the city (e.g., globally or nationally) then although experimentation is instantiated in a place the pressures and social interests shaping experimentation extend far beyond the city. There is a need to better connect differentiated place-based processes of experimentation with the wider forms of governance experimentation that structures and conditions these differentiated urban responses. In short, it is important to recognise that development of the city through experimental processes is not only driven 'endogenously' through a search for place-based autonomy and discretion [43,44]; but that it is also constituted as part of 'exogenous', processes of global urban restructuring [11].

One strand of thinking has challenged the primacy of the city as focus of urban analyses shifting emphasis to global processes of urbanisation, the de-territorialisation and re-territorialisation of global flows and the multiplicity of spatial forms this produces [11]. From these global urban flows, spatial forms are configured through infrastructures, interests and institutions at multiple scales. How configurations of infrastructures and social and institutional interests re-shape flows of people, resources and discourses into, through and out of the city is a critical issue in both maintaining and challenging unequal power relationships [45]. In the struggles of social and institutional interests to govern the reconfiguration of infrastructures and shape metabolic flows in different ways competing conceptions of sustainability are mobilized.

There may be efforts to promote more local, circular and 'self-sufficient' economies at the level of the city. Flows may also be extended through cities acting as nodes within wider extra-state infrastructural configurations [46]. These processes are not zero-sum and they may co-exist as contradictory strategies [47]; as both bounded sites of experimentation and processes of experimentation that break boundaries and build new connections beyond the city. This challenges technocratic policy routemaps and recipes in dealing with uncertainty.

The point of this discussion is that there is no single way of thinking about urban experimentation. That is to say, 'in the study of experimentation there is a wide variety of goals and values, theoretical underpinnings, and discursive emphasis, actors and places' [48] (p. 16). Its focus can be understood as both bounded and unbounded and as relating to socio-technical systems and urban governance arrangements. Recent work has sought to make some sense of the variety of studies on urban experimentation $[48,49]$. Frans Sengers and colleagues have suggested that experiments can be analysed along six dimensions as to the degree to which they are inclusive, systemic, practice-based, challenge-led, sites of social learning, and adaptive in the face of uncertainty and ambiguity in shaping socio-technical change. They point out that in actuality, 'distinctions between types of experiments are actually much more subtle and fluid' [48] (p. 20). Similarly, in their discussion of relationships between transitions management and local governance approaches Julia Wittmayer and colleagues engage with the issue of how sustainability in towns, cities and neighbourhoods is governed and how 'sustainability is made meaningful locally in collaborative processes' [49] (p. 939). They point out that although a radical orientation is necessary for governing urban sustainability this is confronted with the status quo of governing in practice. Their point is that 'governing sustainability should be about finding creative ways for opening spaces for participation, change, and experimentation, that is, for creating alternative ideas, practices, and social relations' [49] (p. 939). This discussion suggests that not only can urban experimentation be understood in many ways but that it is also about trying to categorise and identify 'types' of experiments whilst also recognising that urban experimentation is also a fluid and reflexive process of making the future which is constituted through doing and learning rather than being knowable a priori. 
It suggests that we focus on a looser view of experimental processes rather than with tightly bounded conceptions of experimentation. A looser view of experimental processes seeks to build understanding of uncertain attempts to reconfigure infrastructures, through socio-technical experimentation in place and how this is being shaped by governance experimentation as a response to crises.

\subsection{Three Key Issues from Multiplicity in Urban Transitions}

In this section we summarise the significance of this discussion of urban transitions and draw out three key issues to take forward in the next section of the paper.

Experimentation has become increasingly normalised as a means through which urban transitions is pursued. By definition, the embedding of an infrastructure or a scheme in a particular place-even if this infrastructure or scheme is well-established elsewhere-is about learning about the local governance networks that need to be constructed and material context that needs to be adapted to embed a generic technology or scheme. This is neither the unspecific focus on experiments as 'change' that is prevalent in some discussions of urban experimentation nor is it a tightly specified notion of purposive, bounded experimentation [38]. We suggest that a wider view of urban experimental processes is needed, of assembling technologies, social interests, and new modes of governing into place-based configurations and learning about these processes of embedding an infrastructure or a scheme in a particular place. (1) Material relationships between infrastructures or schemes that are being embedded through experimental processes and wider pre-existing urban infrastructure systems needs to be better understood.

Experimental processes of embedding do not take place in hermetically sealed laboratories. They not only take place in cities which have pre-existing infrastructure systems but also that have pre-existing institutional arrangements that support them. Beyond instantiating activity in a place, experimental processes often underplay or ignore the 'local' institutional configurations within multi-level governance frameworks that establish visions or plans for transition in particular cities. Better understanding is needed of how institutional configurations envisaging transitions [6] link to experimental processes of embedding; (2) Relationships between pre-existing governance arrangements and new governance networks involved in embedding through experimentation need to be better understood.

Within both experimental processes of embedding and pre-existing urban infrastructure configurations a range of economic, ecological and social priorities are contained, which can be competing or complementary. Some of these concerns may be locally-specific and some more generic. This could include a concern with local economic development, air quality, $\mathrm{CO}_{2}$ emissions reduction, resource security, addressing congestion and so on. This suggests the potential for multiple views of 'sustainability' concerns to co-exist in shaping both experimental processes and governance configurations; (3) Better understanding of how multiple conceptions of sustainability shape urban experimental processes is needed.

In understanding how experimental processes, governance configurations and multiple sustainability concerns come together and are reconfigured to shape urban transitions in particular cities there is the potential, as Gavin Bridge and colleagues point out [7], for a multiplicity of responses and much spatial variety and unevenness. This discussion suggests a need to extend current debates on urban transitions.

\section{Methodology}

The literature review, in the previous section, summarised urban sustainability transitions research, engaging with its leading contributions over the last decade or so, to set out the current state of the field. Through the review, three issues were identified that require further elaboration for debates to progress. These were (1) that in actual urban contexts a looser view is needed of how experimental processes seek to reconfigure infrastructures through embedding or grounding (multiple) innovations in a tangible context (the city). This requires a need to understand not only the existing configuration of infrastructure in a city but also (2) that 'local' institutional configurations in a given 
city are likely to be able to mobilise variable resources and capability to differentially shape these processes of embedding (multiple) innovations. Furthermore, with the aim of an urban sustainability transition; (3) the different actors within a city involved in these processes are likely to bring multiple views of sustainability to this. The focus of the paper, therefore, is not just about widening experimental processes but also the relationships between them and local institutional contexts and sustainability discourses shaping them. Taken together, the issue is how these three issues contribute to complex, interweaved patterns, or reconfiguration [50], of existing urban infrastructure systems rather than a sharp disruptive transition.

The aim of the paper is to add to the urban sustainable transitions literature through developing these three extensions into to a framework for future research on systematic urban reconfiguration. This has hitherto not been effectively addressed. Understanding reconfiguration in a systematic way requires conceptual work. We begin this process through developing the three extensions. But, recognising the limits of this within a paper, we address this further through drafting a preliminary framework for future empirical research. The approach of the paper is propositional and generative; moving from the three extensions in the literature and developing these further through reflexive movement via insights from sustainable urban mobility literatures and urban governance in Section 4 . The purpose of Section 4 is not to provide a detailed case study of sustainable urban mobility. Empirical illustrations were selected to enable the conceptual elaboration of the framework; and were drawn from existing academic studies on urban mobility, mostly from the urban and transport studies literature. Doing this within the parameters of a journal article has its limits. There is a need for systematic empirical work that interrogates the three extensions further. This necessitates the development of the preliminary framework for future research.

This means that in Section 5 we use the arguments, provisionally set out in Section 4, to extend these categories further and develop a draft framework for future empirical interrogation of processes of reconfiguration of sustainable urban infrastructure. These are analytically structured using the three extensions. Within each of the three extensions: an analytical focus is summarised; how, analytically, reconfiguration can be understood is set out; and key research issues are identified.

In making our argument, analysis was undertaken through a process of ongoing iteration between the conceptual extensions generated by the literature review and further interrogation of literatures in Section 4. This was part of a reflexive process of becoming familiar with the literature [51] and building conceptual categories [52] via this process. Of course the framework cannot cover all possibilities but application of it through future case study research provides a basis for not only understanding urban reconfiguration processes but also for comparability. Given that there is variety and similarities across cities andurban contexts there is the potential for reconfiguration to exhibit both great difference and similarities. The concern in developing the framework is both with recognising that researching reconfiguration requires both an 'epistemology of the particular' [53] and comparability between urban contexts [54]. In addressing this, 'generalisability' is to the three conceptual propositions. We are proposing that the three part framework is a general approach for studying sustainable urban reconfiguration, not specifically what was discovered about mobility.

We expect the framework to 'work' for other domains (but, the patterns may be different) and it could be used comparatively to better explain why urban sustainability reconfiguration plays out differently across mobility, energy, waste and other areas of provision in urban contexts. It is to be used in researching tangible processes of reconfiguration, grounded in urban contexts. But, also, by setting out three common issues informing reconfiguration there is the basis for subsequent development of comparative analysis of forms of reconfiguration between urban contexts. By developing a preliminary framework to research the reconfiguration of these in actual existing (grounded) urban contexts the aim is to reflexively enhance both a future understanding of reconfiguration processes in urban contexts and to use these insights to revise the preliminary framework. In this sense, the argument developed in the paper is the beginnings of an ongoing process of conceptual and empirical development to research the sustainable reconfiguration of urban contexts. 


\section{Extending Urban Transitions: Towards Contextual Reconfiguration}

With this discussion in mind, there is a need to extend our understanding of urban transitions. How we understand urban transitions runs the danger of meeting too many concepts and overwhelming and confusing empirical material. There is a need to re-focus analytically and conceptualise how the multiple elements (systems and experiments, forms of governance, conceptions of sustainability) are organised in reconfiguring cities and systems, in a particular place. This requires developing a contextual conceptualisation of what has been characterised as a reconfiguration perspective. This 'would pay more attention to adoption and adjustments in existing systems and the (re)alignments between multiple new and old elements that reconfigure system architectures' [50] (p. 7, original emphasis). In thinking about reconfiguration in context we need to go beyond a focus on the old and the new (systems and experiments) in system change. We also need to think seriously about re-alignments between old and new forms of urban governance and old and new conceptions of urban sustainability in particular places.

To conceptually structure an understanding of contextual reconfiguration, we use the lens of selective examples from urban transport infrastructure in the UK, addressing three interrelated issues. First, we need to recognise that in re-shaping systems, experimental processes often cut across and reconfigure relationships between multiple systems (e.g., automobility, rail, bus, cycling). Second, a focus on both institutional concerns and processes of experimentation-rather than either-in multi-level urban governance processes is important. Third, competing conceptions of sustainability set out a range of possibilities about what kinds of infrastructure interventions are possible and desirable. These three issues need to be incorporated into an extended understanding of urban transitions.

\subsection{Experimental Processes at the Interface of Systems and Cities}

As a precursor to contextual reconfiguration, better analytical understanding is needed of how existing relationships between specific cities and infrastructure systems are configured. Existing relationships between cities and infrastructure systems are based on relationships of stronger and weaker correspondence where the ability of system interests to intervene, govern and shape systems at the level of the city are variable. Mobility of people, goods and services into through and out of cities, for example, is mediated by multiple transport systems (automobility, rail, bus, cycling, aviation, shipping systems and so on). The organisation of each of these systems has a variable correspondence with the administrative organisation of territorial space. There is, for example, weak correspondence between the city as a scale of organisation and the automobility system. The automobility system is strongly governed by regimes of corporate automobile manufacturers within global supply chains, their alliances with national governments and oil interests [55]. Much physical infrastructure-roads, fuel stations etc.-is often organised within national space. Many of these elements are present in this city but they are not largely organised at this scale. Likewise, there is weak correspondence of this kind between cities and aviation systems, where cities may be seen as nodes within a wider global system. Rail has some organisation of the system at the level of the city but this is often within the organisational framework of a national rail system. Arguably there is greater correspondence between the city as a scale of organisation for bus, cycling and light rail systems where the vast majority of trips are 'local' [56]. In the case of buses, parts of the rail system, light rail and cycling, systems of operators and users are organised as part of local transport systems. That is not to say that there is not a key role for non-local interests-there is, as the role of the UK state in bus deregulation and liberalisation in the 1980s illustrates [57,58], for example, and in producing a fragmented cycling system [59]—but it does demonstrate a level of correspondence between the city and these systems.

With this variability in mind, it is important to develop understanding of how instantiations of place-based experimental processes of embedding selective innovations reconfigures systems at the level of the city. There are potentially multiple innovative possibilities that contribute to the reconfiguration of urban mobility, from battery electric vehicles (BEVs) to urban bike hire schemes and from the promotion of cycling lanes and infrastructure to inter-modal ticketing schemes and many 
more. What is clear is that it is often not the artefact or technology that is particularly innovative. There is nothing particularly novel and innovative about a bike or a credit card-sized piece of plastic. What is often innovative is the (variable) experimental processes through which artefacts are configured and organised in territorial contexts [2] and how these relate to existing systems. We can illustrate this point by taking one example, in one city: a bike sharing scheme in Greater London.

In many ways, bicycle-sharing schemes can be seen as 'generic' interventions in mobility systems. There has been significant growth in the numbers of bicycle-sharing schemes and fleets worldwide particularly since 2007. Schemes fuse together bike-share systems with smartcard technology, electronic payments systems and self-service bicycle stations that link with a central computer and GPS technology to monitor the location of bicycles in the system. Websites also offer real-time data on availability of bikes at particular stations [60]. Urban decision-makers are prioritising bike-sharing to contribute to enhancing mobility, addressing congestion, reducing air pollution and promoting health benefits through reducing car use by integrating them into multi-modal mobility systems $[60,61]$. How a scheme was embedded in Greater London takes learning from the Paris Velib scheme, which has been something of an exemplar for other cities [62]. But the specificity of Greater London also requires the embedding of a bicycle-sharing scheme through experimental processes of new capacity being built and configured. This is done in ways which connect to effective pre-existing public transport systems, forms of demand management policy [60] and the development by cities of comprehensive bike-sharing strategies [63]. The UK's largest scheme-around 8000 bikes and 500 docking stations by 2014 with plans for further expansion [64] commenced operation in Greater London in 2010. The scheme is operated by the outsourcing company, SERCO, for Transport for London [65] and sponsored by Barclays Bank [66]. The scheme was expected to cost $£ 140$ m over six years [67]. In Greater London, there was significant policy-driven growth in cycling with trips by bike increasing 79\% between 2001 and 2011, with this amounting to a 173\% increase in central and inner London [68] (p. 5). A strategy for cycling was set out in 2001 [69], there was the establishment of a Congestion Charge scheme for the urban core of London in 2003 and its extension in 2007, and designated bus lanes were available to cyclists. By 2008/9 the mayor of London had pledged $£ 62 \mathrm{~m}$ for walking and cycling which was five times higher than five years previously [70]. Experimental processes of embedding the bicycle-sharing scheme in Greater London drew on learning from pre-existing schemes (e.g., Paris Velib) and building governance networks as part of that process of embedding.

The point to be made from the discussion above is that innovation is not with an artefact per se but is in processes of embedding and the reconfiguration or 'diffusion' this necessitates. The local context, its path dependencies in existing transport systems, governance, politics and forms of funding are key in shaping such processes [2]. Innovations that may be radical in some cities are the norm in others. This is likely to require empirical and comparative exploration of different urban contexts. In the UK, work has shown how 'clear differences' exist between city-specific trajectories where, for example, electric mobility is promoted in Oxford and cycling innovations in Brighton [2]. This highlights variable place-based capability to shape experimental processes and variable effects.

This discussion illustrates that experimental processes of embedding urban mobility innovations are in many ways spatially-specific attempts that contribute to the reconfiguration of the prevailing organisation of mobility. It is not just single innovations but experimental processes of embedding a multiplicity of infrastructures or schemes simultaneously in a city that needs to be better understood. And if what is novel is the process and forms of governance and organisation through which artefacts and material infrastructure are diffused and embedded in a particular context then how multiple innovations are configured in a context and what the relationships are between them is a key issue. Analytically this is a challenge for singular MLP studies that often understand transitions as one niche-innovation struggling against one regime. While such singular transitions do occur, the city usually provides a context for 'a large number and diverse range of innovations and their linkages in geographical contexts where multiple regimes-auto-, bus- and velomobility-compete, coexist and intermingle (While the terms 'compete' and 'coexist' are relatively clear that of 'intermingle' 
is somewhat 'fuzzy'. For the purposes of clarity, we use the term 'complement' rather than 'intermingle' $)^{\prime}$ [2] (p. 7090). This means 'this image of a decisive [transition] switch may exaggerate the potential for closure in what is likely to be a very messy and open ended process' [71] (p. 328). It also suggests that the 'unit of analysis is not a given, nor a matter of accurate, objective analysis, but an issue of strategic choice' where 'normative views, and estimates of what interlinkages may create promising opportunities for change, all come together in a process of political judgement' [72] (p. 68). Urban transitions need to be understood to involve a diverse range of innovations that are variably configured at the level of the city; where transition is more open-ended than sharp disjuncture; and where there is considerable responsibility on the researcher in framing the unit of analysis.

\subsection{Connecting Urban Experimental Processes with Multi-Level Urban Governance}

In this section we set out why it is important to connect together analysis that focuses on the city as a context where urban experimental processes of embedding take place with processes of urban governance. The city may be where (a particular kind of) urban transition manifests but wider global-urban flows and processes-global economic restructuring and its implications for work, consumption and mobility; the development of 'replicable' global infrastructures, global agreements on carbon reduction and so on-frame a set of conditions and possibilities [11,46,73]. These possibilities are mediated and selectively interpreted by the institutional and governance frameworks claiming to speak on behalf of a city [74,75] (or indeed other spatial forms, such as a zone, a corridor or a region given the challenge to the dominance of the city as a unit of analysis). The view of the city as a single, connected, independent entity that can be represented through a dominant lens has been questioned [76]. We set out a dominant lens here as one lens. Previous and future work uses other lenses and addresses 'alternative' claims to the city). Cities are not bounded containers but embedded, territorial contexts within wider relational networks of flows. Different place-specific configurations contribute to uneven processes of urban transitions which need to be understood analytically.

Urban experimental processes should, thus, be understood within wider global processes beyond place-specific contexts or sites. This requires acknowledgment that for more than three decades 'neoliberalism has defined the broad trajectory of urban restructuring, never predetermining local outcomes on the ground as if some iron law, but nevertheless profoundly shaping the ideological and operational parameters of urbanization' [74] (p. 1091). To push this argument further, it is not that cities crudely receive 'recipes' of imposed neoliberal responses, institutional formations and routines. Responses may circulate as global infrastructures, agreements, targets and policy mobilities [77]. In our terms, this may mean the promotion of 'solutions' such as battery electric vehicles, self-driving cars, or urban bike hire schemes, urban car clubs and so on. But these are not simply replicable. They become differentially embedded in cities. Being adopted in some and not in others; and being embedded in specific system and governance configurations where they are adopted. 'Cities' mediate between these global circulations and their uneven territorial embedding [27]. In this line of thinking, cities 'are better understood as institutional forcefields positioned within (and continuously transformed through) an always mutating and unevenly developed landscape of regulatory reform, experimentation, circulation, failure, (re)consolidation and crisis' where as well as dominant conceptions of transitions 'there are always countervailing interests, pressures and visions' [74] (p. 1093). Taking such a position requires that we understand how urban experimental processes are shaped but not determined beyond the 'local' context of the city by multi-scalar power relations that 'include large-scale institutional ensembles, financial systems and monetary arrangements, and international organizations that variously frame, formulate, finance and sometimes even fulfil policy programs across diverse sites' [74] (p. 1097).

Beyond this focus on the conditioning of urban transitions, there is also a need to understand the mechanisms of circulation and how they are mediated. This also requires assessing the role that national state institutions play in configuring and enrolling city governance frameworks to develop experimental processes in certain ways. Recent work on urban energy-carbon has outlined five modes of enrolment that state actors use to enact such processes: classical-modernist state fiscal and regulatory 
levers; a calculative instrumentalism where through spatial emissions targets the UK state has sought to create a territorial framework for action on carbon reduction; a strategically selective enabling role of the state in promoting place-based entrepreneurial activity; a marketised individualisation where state interventions by-pass city institutions in ways which directly focus experimental measures on individuals and communities; and the construction of new energy communities through processes of experimentation promoted by national policy [78]. These different modes shape 'experimentation in implementation, [where] atomisation [in experimentation] is a result of tensions created by a range of ... different challenges and path-dependencies...' [78] (p. 8). This means that a productive dialogue is needed between neo-institutional concerns and experimental processes rather than a focus on one or the other.

\subsection{Sustainable Urban Mobility as Orientation for Infrastructural Possibilities}

These two previous sections are important in setting out the interface of systems and cities as the focus of urban experimental processes; and also the need to understand this as part of wider urban governance processes. But this leaves the issue of to what extent these processes can help us understand transitions to sustainable urban mobility rather than 'merely' transitions in urban transport systems. Sustainable mobility, as an approach, is a response to the unsustainability of current ways of organising mobility systems. What is meant by sustainable mobility, though, is less than clear and 'often covers disagreement, in particular about the fundamental strategic question of whether the dominant reliance on the car needs to be reduced or whether the system of automobility can be transformed into a sustainable one' [79] (p. 304). What sustainable mobility looks like tangibly is a menu of possibilities and it is important to think beyond single technologies and innovations and to utilise a coherent conceptualisation. One pre-eminent 'sustainable mobility approach' [80] (pp. 75-76) characterises four sets of actions, which we summarise.

First, is the issue of reducing the need to travel and not making trips through, for example, teleworking, teleconferencing or via internet shopping [81]. Second, encouraging modal shift is intended to be a contribution to reducing car use through combinations of measures slowing traffic, re-designating road space for non-car transport and other activities and promoting shifts to other modes of mobility such as walking, cycling and the promotion of tram and light rail developments [82]. Third, reducing trip lengths sees various long-term visions integrate sustainable mobility with plans to re-think and re-design cities as compact cities, smart cities and even traffic-free cities [83]. Fourth, encouraging greater efficiency in the transport system involves promoting the use of new engine and fuel technologies, and through standards and obligations on manufacturers, to build greater transport efficiencies in existing vehicles, develop new forms of powertrain and reduce carbon emissions [84]. This neat conceptualisation illustrates the multi-system and multi-pathway nature of any change to more sustainable forms of mobility where 'much of the literature relates to the difficulty if not the impossibility of effective implementation of sustainable mobility' [80] (p. 76).

Yet, each of these pathways is contested. To take the example of reducing the need to travel; to what extent can urban mobility experiments contribute to this? Teleworking, teleconferencing or internet shopping through the use of ICTs, internet and Wi-Fi capability, PCs and laptop computers and mobile phone technology creates a context where almost $14 \%$ of the UK workforce are 'home workers' [85], with complex consequences for mobility patterns (see [86]). 'Home worker' is a broad category and should be treated with some care; but in many ways, significant amounts of homeworking can be understood as part of wider processes of economic restructuring that reconfigures mobility flows. This is not done through purposive experimentation with mobility systems per se but is through changes in the organisation of work and production-consumption relations that are being driven by the shift to an information society. To take another contested example, compact cities have the aim of reducing trip lengths through the design and integration of urban form, urban living and transport systems. Underpinning this is academic work which demonstrates that higher population density results in fuel consumption falling significantly [83]. There is no accepted definition of a compact 
city $[87,88]$ but it is often seen as counter to problems created by urban sprawl and processes of suburbanization $[87,89]$ and seeks to build more sustainable ways of organising cities. Practically, this usually means combinations of measures to promote reduced and cleaner car use and public transport and active modes of travel. Though there is a substantial literature, empirical evidence on compact cities is mixed and often contradictory [90]. The compact city paradox suggests compaction requires concentration of functions and populations but that liveable cities require lower density populations and functions [87]. Density patterns have become more complex over the last fifty years [91] where urban form can be understood not only as monocentric but also as polycentric metropolitan regions [92]. This has implications for the scale at which compaction happens and also whether this can be governed by public policy and planners [91]. In short, compact cities may be sustainable in some areas and not so in others with sustainability gains, losses and trade-offs [93].

We can see in these examples that conceptions of sustainable urban mobility start to become muddied with multiple other concepts; here notions of compact cities, liveable cities and 'smart' forms of working and shopping. The point of these two examples is that even if the purpose of sustainable urban mobility is stated, then what this means is often contested. The 'sustainability' concerns that mediate concrete experimental processes with urban mobility in different urban contexts are a site of these struggles and others. Sustainable urban mobility provides orientation and a suite of possibilities rather than a prescribed route map. It will be apparent from the argument made so far that thinking productively about transitions to urban sustainable mobility cannot be via a prescriptive process. Urban transitions involve a diverse range of experimental processes, forms of governance and sustainability concerns and the need is to understand how these are configured at the level of the city. Given the concerns of urban transitions with multiplicity and spatial variability how these issues inform reconfiguration is likely to be variable and requires understanding of this.

\section{Towards a Framework: Analysing Variability in Forms of Reconfigurations}

Reconfiguration will vary and be uneven between places [94]. Multiple manifestations of contextual reconfiguration suggests that a focus on the variety of forms of reconfiguration in context is necessary to understand urban transitions. Forms of reconfiguration-given that they combine the old and the new-are by definition emergent. They can be understood through addressing how existing configurations of systems, urban governance and conceptions of sustainability in a city are reconfigured through experimental processes. An analytical focus on the relationships between existing configurations (old) and experimental assemblages [95] (new) allows us to understand the potential variability in forms of reconfigurations in different cities. Analytically, it is important to build comparability between these forms of reconfiguration in different city contexts. To do this, we draw on insights from the previous sections, and disentangle reconfiguration thinking through setting out a preliminary framework with three analytical points of entry: (1) socio-technical arrangements; (2) forms of urban governance; and (3) conceptions of urban sustainability (see Table 1). For each of these three points we articulate a focus, set out analytical challenges posed by reconfiguration, and highlight the research requirements that follow. In this respect, we sketch out propositions for future research to interrogate, populate and build on. 
Table 1. A Preliminary Framework; Forms of Reconfiguration as a Focus of Analysis of Urban Transitions.

\section{Three Common Issues Informing Reconfigurations}

Focus: how a large number of sustainability innovations compete, coexist and complement [2] within a particular city

Analysing reconfiguration: requires understanding analytically what reconfiguration looks like in three areas:

Competing-Struggles between new vs new or new vs old socio-technical arrangements

New configurations of

Co-existing-Parallel and largely independent socio-technical arrangements

multiple socio-technical

experiments and

existing systems

Complementary-Productively fused relationships of new and new/old socio-technical arrangements

Key research issue: Do experimental processes of embedding sustainable urban infrastructures and schemes provide the potential to

reconfigure systems at the city-scale and in what ways? This requires:

Conceptual and empirical understanding at the interface of experimental processes and systems

City-specific trajectories mean that there is need for typologies of different analytical connections between multiple experimental processes

Focus: how interactions between multiple forms of urban governance condition and shape urban experimental processes Analysing reconfiguration: a lot of distributed and fragmented governance capacity means there are potentially multiple modes of governance competing, co-existing and complementing in a city and which can be characterised as follows: Competing-Fragmented and mutually hostile/contradictory governance arrangements

Co-existing-Fragmented, distinct and either autonomous or loosely coupled governance arrangements

Shaped by multiple forms Complementary-Symbiotic/mutually reinforcing governance arrangements producing new forms of hybrid governance

of urban governance

Key research issue: New fusions and forms of urban governance are emerging that don't fit easily within existing typologies [37]. This requires that research:

Engages systematically with developing understanding of how wider global flows and infrastructure 'solutions' are mediated by multi-level governance and institutional architectures in reconfiguring urban forms

Requires building dialogue between assessment of complex, new fusion and forms of urban governance, whether these can be understood through existing governance typologies and what implications this has for theories of urban governance

Focus: what accounts of sustainability become dominant in shaping experimental processes and who is promoting them?

Analysing reconfiguration: In any given city, a concern with 'urban sustainability' is likely to be built on multiple, often competing,

co-existing and complimentary, negotiations and fusions of accounts of what is understood by sustainability, that can be understood as:

Competing understandings and orientations for sustainability goals

Mediated by multiple understandings of urban sustainability Co-existing-Parallel and largely nonconflictual understandings and orientations

Complimentary-Mutually reinforcing or comprised through issue linkage between alternative sustainability understandings and orientations

Key research issue: To understand how multiple accounts of sustainability are interpreted, negotiated and coordinated (or not) in shaping experiments and reconfiguration. This requires:

Understanding the consequences of multiple accounts of urban sustainability in a city for experimental processes and reconfiguration Building comparative understanding of this across cities 


\subsection{Reconfiguring Relationships between Systems and Urban Experimental Processes}

In previous sections, we discussed how the search for more sustainable forms of mobility (or energy, water, waste) involves experimental processes with a diverse range of technological and social innovations in a city. It is important to move beyond single innovations and to address: what do all these experimental processes add up to in a city? The challenge is not to understand how a single innovation, as a niche, contributes to transport regime transitions at the level of the city. Rather the focus should be on how a rather large number of sustainable transport (or energy, water, waste) innovations compete, coexist and complement [2] at the level of the city. In processes of reconfiguration, this requires understanding the forms of connections that different experimental processes have with (1) each other and (2) with the existing system(s). On the first of these, there is some evidence that many urban sustainability experiments in the UK are episodic interventions with a lack of strategic connection [44,78]. On the second of these issues, urban experimentation with sustainable transport innovation does not take place in a 'clean' laboratory but in actually existing urban contexts. It is important to understand how these experimental processes relate to existing transport systems in the city. We have seen that the correspondence between transport systems and cities is variable. What is of interest here is the potential that experimental processes with urban sustainable mobility provide to reconfigure systems at the city-scale and in what ways they do so. This means, through empirical exploration, building analytical understandings of relationships between multiple experimental processes and systems in a city and whether the effects produce competing, co-existing or complimentary forms of relationships. That is to say, whether we can understand multiplicity as involving struggles between new versus new or new versus old socio-technical arrangements (competing); or whether multiplicity produces parallel and largely independent socio-technical arrangements (co-existing); or it results in complimentary new fusions between new and new/old socio-technical arrangements. A conceptual lexicon needs developing to address relationships or lack of them between multiple experimental processes; one that is grounded in empirical understanding of these relationships in different urban contexts. This requires future research to engage with conceptual and empirical understanding of how relationships between experimental processes and multiple systems in particular urban contexts are reconfigured. City-specific trajectories of contextual reconfiguration mean that there is a need for comparative empirical research to inform the development of typologies.

\subsection{Reconfiguring Forms of Urban Governance}

New modes of governance are assembled in shaping reconfiguration of systems through experimental processes. This involves a range of existing and new institutional and social interests at different political and policy scales $[96,97]$. This produces multiple forms of experimental urban governance [28]; which adds up to a lot of distributed and fragmented governance capacity seeking in some way-some complimentary and some contradictory-to maintain or reconfigure parts of a system and the boundaries of the city. There are potentially multiple modes of governance competing, co-existing and complimentary in a city. The key analytical challenge is to understand how multiple modes of governance relate to each other and how they are reconfigured in particular cities. It has been suggested that new forms of urban governance are emerging that don't fit easily within existing typologies [37]. It is, thus, important to understand the multiplicity of forms of urban governance that are shaping reconfiguration of systems and experimental processes. This is easier said than done and involves complex multi-level governance arrangements [98]. Multiple forms of governance emerge in reconfiguration that involves existing and experimental forms of urban governance (the old and the new). In particular place-based configurations (constituted by global governance, national state and local governance interests) analytical understanding is needed of how multiple forms of multi-scalar urban governance within a city relate to each other [37]. This requires an analytical focus on three issues. First, whether the multiplicity of urban governance arrangements in a place can be understood as fragmented and predicated on mutually hostile/contradictory governance 
arrangements (competing); or, second, whether multiplicity produces fragmented, distinct and either autonomous or loosely coupled governance arrangements (co-existing); or, third, whether multiplicity results in symbiotic/mutually reinforcing arrangements and new forms of complimentary governance. This requires that research engages systematically with developing understanding of processes between wider 'global' institutional architectures and reconfigured urban forms. It also means building dialogue between assessments of complex, new forms of urban governance, whether these can be understood through existing governance typologies and what implications this has for theories of urban governance.

\subsection{Mediated by Multiple Understandings of Urban Sustainability}

It's hardly revelatory to suggest that understandings of 'sustainability' are contested. Yet, this has significant implications for the ways in which governance shapes reconfiguration of cities and urban systems. The interface of two issues is key here. The first issue is that what is meant by 'urban sustainability' - never an easy term to pin down — has arguably become even slippier since the 2007-2008 financial crisis [14,99]. In policy and academic debates, 'sustainable city' discourse jostles with those of smart cities, eco-cities, green cities, resilient cities and combinations of these such as 'smart, sustainable cities' [100]. There also appears to be some slippage and interchangeability in use between these concepts; although it is claimed they show significant conceptual differences. The significance of this is that each of these city categories addresses relationships between economy, environment and urban society differently [100]. This is important because multiple conceptions of urban sustainability are mobilised and carried by the various different governance interests shaping reconfiguration. Within governance configurations the very basis of what sustainability might mean when it informs contextual reconfiguration-how much and what kinds of economic growth, what role there is for transport in that, what emphasis is put on carbon emissions versus growth, issues of social cohesion and so on-is subject to negotiation between multiple actors in governance configurations. Given the fragmented and distributed range of interests that are involved in the governance of reconfiguration, there is the basis for a range of different interpretations informing practices of 'urban sustainability'. There may be reconfiguration but how does a concern with 'urban sustainability' mediate such processes? In any given city, there are likely to be multiple competing, co-existing and complimentary accounts of urban sustainability. This may produce competing understandings and orientations for sustainability goals; or it may result in parallel and largely non-conflictual understandings and orientations towards sustainability (co-existing); or, multiplicity may see mutually reinforcing conceptions through issue linkage between alternative sustainability orientations and understandings (complimentary). In processes of interpretation, negotiation and coordination, conceptions of sustainability start to become muddied with multiple other concepts such as efforts to make urban infrastructure systems 'smarter', more resilient, more low carbon and so on [14]. The analytical issue this raises is, what accounts of urban sustainability become dominant in shaping reconfiguration and who is promoting them? Is this a single account or is it a consequence of multiple accounts of sustainability? In research terms, this requires developing better understanding of processes of interpretation, negotiation and coordination of multiple accounts of sustainability in a city and the understandings of sustainabilities that are produced. There is also a need to understand this comparatively across cities.

\section{Conclusions: Embracing Multiplicity and Future Directions}

In this paper we have sought to contribute to debates around urban sustainability transitions by developing a way of understanding the variability and uneveness of urban infrastructure transitions on the ground. To do this, we discussed current trends in urban transitions research, offering a synthetic account of its development. Engaging with urban sustainable mobility, we highlighted the need for extending understandings in urban transitions approaches to better connect experimentation 
with systems and spaces, multi-level processes of urban governance and understandings of urban sustainability.

The paper set out the multiplicity of different possibilities that each of these opens up and which, in combinations, make the potential of urban sustainable mobility almost overwhelming. To address this, we developed a preliminary framework that embraced this variability. We highlighted the need for a focus on the form of reconfiguration, informed by multiple issues in a particular city. Recognising that without some order that each reconfiguration in a different city would remain specific we developed an analytical focus on three themes of reconfiguration to bring some commonality for analysis of reconfigurations.

We are aware of both the ambition and the limits of such a framework. In the confines of a paper, our contribution has been to develop a preliminary framework for researching urban transitions that builds from an existing body of literature and engages seriously with multiple radically contested concepts. But this is a first step. The primary tension our work speaks to is between the possibilities to inform change through technological and social innovations, which are many, and the grounded and fragmented capacity and capability to be able to shape change. We have sought to build a preliminary framework that engages with this tension productively. Rather than be overwhelmed by multiplicities and variabilities we embraced this through the concept of reconfiguration. We call for future research to engage with this framework.

In setting out the framework in the paper we have not had space to discuss its application. Methodologically, there are numerous ways in which this kind of contextual reconfiguration approach could be mobilised. But in particular, this focus would benefit from theoretically-informed ethnographic work. This would seek to illuminate both forms and processes of reconfiguration in individual cities. Empirical work would seek to understand reconfigurations drawing collectively on all three themes and what they add up to in individual cities. This kind of approach could be used to understand sustainable mobility and the city but also energy, water, waste and nexus approaches that seek to integrate them. Furthermore, there would also be benefit from undertaking comparative work assessing reconfigurations between different cities. This form of comparison would allow the building of typologies of forms and processes of reconfiguration in transitions to sustainable urban mobility (or energy, waste etc.). Such typologies would also contribute empirical insights back to further conceptual modifications of the framework.

Theoretical, conceptual and empirical work is needed to strengthen understanding of these unstable categories and how they interrelate. The danger is, that this instability leads to not knowing how to research such complexity. This framework, and our call for engaging with it, seeks to contribute to countering that.

Acknowledgments: The research in this paper was supported by the Framework 7 PATHWAYS project (Grant Agreement No. 603942). The authors are grateful for the helpful comments of three reviewers.

Author Contributions: The argument in this paper was developed from the three authors' work in the FP7 PATHWAYS project. Six project reports produced jointly by the authors have informed the theoretical, conceptual and empirical basis of the paper. Mike Hodson led the writing of the paper.

Conflicts of Interest: The authors declare no conflict of interest.

\section{References}

1. Wolfram, M.; Frantzeskaki, N. Cities and Systemic Change for Sustainability: Prevailing Epistemologies and an Emerging Research Agenda. Sustainability 2016, 8, 144. [CrossRef]

2. Schwanen, T. The Bumpy Road toward Low-Energy Urban Mobility: Case Studies from Two UK Cities. Sustainability 2015, 7, 7086-7111. [CrossRef]

3. Truffer, B.; Murphy, J.T.; Raven, R.P.J.M. The geography of sustainability transitions: Contours of an emerging theme. Environ. Innov. Soc. Transit. 2015, 17, 63-72. [CrossRef]

4. Coenen, L.; Benneworth, P.; Truffer, B. Toward a spatial perspective on sustainability transitions. Res. Policy 2012, 41, 968-979. [CrossRef] 
5. Hodson, M.; Marvin, S. Can cities shape socio-technical transitions and how would we know if they were? Res. Policy 2010, 39, 477-485. [CrossRef]

6. Rohracher, H.; Späth, P. The Interplay of Urban Energy Policy and Socio-technical Transitions: The Eco-cities of Graz and Freiburg in Retrospect. Urban Stud. 2013, 51, 1415-1431. [CrossRef]

7. Bridge, G.; Bouzarovski, S.; Bradshaw, M.; Eyre, N. Geographies of energy transition: Space, place and the low-carbon economy. Energy Policy 2013, 53, 331-340. [CrossRef]

8. Bulkeley, H.; Castán Broto, V.; Hodson, M.; Marvin, S. (Eds.) Cities and Low Carbon Transitions; Routledge: Abingdon, VA, USA, 2011.

9. Affolderbach, J.; Schulz, C. Mobile transitions: Exploring synergies for urban sustainability research. Urban Stud. 2016, 53, 1942-1957. [CrossRef]

10. Purcell, M. Urban Democracy and the Local Trap. Urban Stud. 2006, 43, 1921-1941. [CrossRef]

11. Brenner, N.; Schmid, C. Towards a new epistemology of the urban? City 2015, 19, 151-182. [CrossRef]

12. Broto, V.C.; Bulkeley, H. A survey of urban climate change experiments in 100 cities. Glob. Environ. Chang. 2013, 23, 92-102. [CrossRef] [PubMed]

13. Hendriks, F. Understanding Good Urban Governance: Essentials, Shifts, and Values. Urban Aff. Rev. 2014, 50, 553-576. [CrossRef]

14. Hodson, M.; Marvin, S. (Eds.) After Sustainable Cities? Routledge: Abingdon, VA, USA, 2014.

15. Rip, A.; Kemp, R. Technological change. Hum. Choices Clim. Chang. 1998, 2, 327-399.

16. Geels, F. Technological transitions as evolutionary reconfiguration processes: A multi-level perspective and a case study. Res. Policy 2002, 31, 1257-1274. [CrossRef]

17. Geels, F.; Schot, J. Typology of sociotechnical transition pathways. Res. Policy 2007, 36, 399-417. [CrossRef]

18. Schot, J.W.; Geels, F.W. Strategic niche management and sustainable innovation journeys: Theory, findings, research agenda and policy. Technol. Anal. Strateg. Manag. 2008, 20, 537-554. [CrossRef]

19. Smith, A.; Raven, R. What is protective space? Reconsidering niches in transitions to sustainability. Res. Policy 2012, 41, 1025-1036. [CrossRef]

20. Van Driel, H.; Schot, J. Radical innovation as a multi-level process: Introducing floating grain elevators in the port of Rotterdam. Technol. Cult. 2005, 46, 51-76. [CrossRef]

21. Smith, A.; Voß, J.; Grin, J. Innovation studies and sustainability transitions: The allure of the multi-level perspective and its challenges. Res. Policy 2010, 39, 435-448. [CrossRef]

22. Smith, A.; Stirling, A.; Berkhout, F. The governance of sustainable socio-technical transitions. Res. Policy 2005, 34, 1491-1510. [CrossRef]

23. Truffer, B.; Coenen, L. Environmental Innovation and Sustainability Transitions in Regional Studies. Reg. Stud. 2012, 46, 1-21. [CrossRef]

24. Raven, R.P.J.M.; Schot, J.; Berkhout, F. Environmental Innovation and Societal Transitions Space and scale in socio-technical transitions. Environ. Innov. Soc. Transit. 2012, 4, 63-78. [CrossRef]

25. Murphy, J.T. Human geography and socio-technical transition studies: Promising intersections. Environ. Innov. Soc. Transit. 2015, 17, 73-91. [CrossRef]

26. Longhurst, N. Towards an 'alternative' geography of innovation: Alternative milieu, socio-cognitive protection and sustainability experimentation. Environ. Innov. Soc. Trans. 2015, 17, 183-198. [CrossRef]

27. Hodson, M.; Marvin, S. Cities Mediating Technological Transitions: Understanding Visions, Intermediation and Consequences. Technol. Anal. Strateg. Manag. 2009, 21, 515-534. [CrossRef]

28. Bulkeley, H.; Castán Broto, V. Government by experiment? Global cities and the governing of climate change. Trans. Inst. Br. Geogr. 2013, 38, 361-375. [CrossRef]

29. Caprotti, F. Eco-Cities and the Transition to Low Carbon Economies; Palgrave-Pivot, Palgrave Macmillan: Basingstoke, UK, 2015.

30. Bouzarovski, S. Retrofitting the City: Residential Flexibility, Resilience and the Built Environment; I.B. Taurus: London, UK, 2015.

31. Hodson, M.; Marvin, S. (Eds.) Retrofitting Cities; Routledge: Abingdon, VA, USA, 2015.

32. Rapoport, E. Utopian Visions and Real Estate Dreams: The Eco-city Past, Present and Future. Geogr. Compass 2014, 8, 138-139. [CrossRef]

33. Hodson, M.; Marvin, S.; Bulkeley, H. The Intermediary Organisation of Low Carbon Cities: A Comparative Analysis of Transitions in Greater London and Greater Manchester. Urban Stud. 2013, 50, 1403-1422. [CrossRef] 
34. Acuto, M. Retrofitting global environmental politics. Networking and climate action in the C40. In Retrofitting Cities: Priorities, Governance and Experimentation; Hodson, M., Marvin, S., Eds.; Routledge: Abingdon, VA, USA, 2015.

35. Bulkeley, H.; Betsill, M. Cities and Climate Change: Urban Sustainability and Global Environmental Governance; Routledge: New York, NY, USA, 2003.

36. Evans, J.; Karvonen, A. Urban laboratories: Experiments in reworking cities. Int. J. Urban Reg. Res. 2014, 38, 2437-2453.

37. Gross, J. Hybridization and Urban Governance: Malleability, Modality, or Mind-Set? Available online: http://journals.sagepub.com/doi/pdf/10.1177/1078087416637127 (accessed on 9 February 2017).

38. Karvonen, A.; van Heur, B. Urban Laboratories: Experiments in Reworking Cities. Int. J. Urban Reg. Res. 2014, 38, 379-392. [CrossRef]

39. Nevens, F.; Frantzeskaki, N.; Gorissen, L.; Loorbach, D. Urban Transition Labs: Co-creating transformative action for sustainable cities. J. Clean. Prod. 2013, 50, 111-122. [CrossRef]

40. Brown, H.S.; Vergragt, P. Bounded socio-technical experiments as agents of systemic change: The case of a zero-energy residential building. Technol. Forecast. Soc. Chang. 2008, 75, 107-130. [CrossRef]

41. Evans, J. Trials and Tribulations: Problematizing the City through/as Urban Experimentation. Geogr. Compass 2016, 10, 429-443. [CrossRef]

42. Oosterlynck, S.; Gonzales, S. 'Don't Waste a Crisis': Opening up the City Yet Again for Neoliberal Experimentation. Int. J. Urban Reg. Res. 2013, 37, 1075-1082. [CrossRef]

43. Bulkeley, H.; Luque-Ayala, A.; McFarlane, C.; MacLeod, G. Enhancing urban autonomy: Towards a new political project for cities. Urban Stud. 2016, in press. [CrossRef]

44. Hodson, M.; Evans, J.; Schliwa, G. Conditioning Experimentation: The struggle for place-based discretion in shaping urban socio-technical transport infrastructures. Environ. Plan. C 2016. under review.

45. Heynen, N.; Kaika, M.; Swyngadouw, E. (Eds.) In the Nature of Cities: Urban Political Ecology and the Politics of Urban Metabolism; Routledge: London, UK, 2006.

46. Easterling, K. Extrastatecraft: The Power of Infrastructure Space; Verso: London, UK, 2014.

47. Broto, V.C. Contradiction, intervention, and urban low carbon transitions. Environ. Plan. D 2015, 33, 460-476.

48. Sengers, F.; Berkhout, F.; Wieczorek, A.; Raven, R. Experimenting in the city: Unpacking notions of experimentation for sustainability. In The Experimental City; Evans, J., Karvonen, A., Raven, R., Eds.; Routledge: Abingdon, VA, USA, 2016.

49. Wittmayer, J.; Van Steenbergen, F.; Rok, A.; Roorda, C. Governing sustainability: A dialogue between Local Agenda 21 and transition management. Local Environ. Int. J. Justice Sustain. 2016, 21, 939-955. [CrossRef]

50. Geels, F.; McMeekin, A.; Mylan, J.; Southerton, D. A critical appraisal of Sustainable Consumption and Production research: The reformist, revolutionary and reconfiguration positions. Glob. Environ. Chang. 2015, 34, 1-12. [CrossRef]

51. May, T. Social Research: Issues, Methods and Process; Open University Press: Buckingham, UK, 2011.

52. Lofland, J.; Lofland, L. Analyzing Social Settings: A Guide to Qualitative Observation and Analysis; Wadsworth: Belmont, CA, USA, 1995.

53. Stake, R.E. Case Studies'. In Handbook of Qualitative Research; Denzin, N.K., Lincoln, Y.S., Eds.; Sage: Thousand Oaks, CA, USA, 1994.

54. McFarlane, C. The Comparative City: Knowledge, Learning, Urbanism. Int. J. Urban Reg. Res. 2010, 34, 725-742. [CrossRef]

55. Geels, F.W. A socio-technical analysis of low-carbon transitions: Introducing the multi-level perspective into transport studies. J. Transp. Geogr. 2012, 24, 471-482. [CrossRef]

56. Department for Transport. National Travel Survey: England. 2013. Available online: https://www. gov.uk/government/uploads/system/uploads/attachment_data/file/342160/nts2013-01.pdf (accessed on 9 February 2017).

57. Cowie, J. Acquisition, efficiency and scale economies: An analysis of the British bus industry. Transp. Rev. Transnatl. Transdiscipl. J. 2002, 22, 147-157. [CrossRef]

58. Langridge, R.; Sealey, R. The demand for public transport: The effects of fares, quality of service, income and car ownership. Transp. Policy 2000, 7, 105-115. [CrossRef]

59. Aldred, R. Governing transport from welfare state to hollow state: The case of cycling in the UK. Transp. Policy 2012, 23, 95-102. [CrossRef] 
60. Midgley, P. Bicycle-Sharing Schemes: Enhancing Sustainable Mobility in Urban Areas. Available online: http://www.un.org/esa/dsd/resources/res_pdfs/csd-19/Background-Paper8-P.Midgley-Bicycle.pdf (accessed on 9 February 2017).

61. Lin, J.; Yang, T. Strategic design of public bicycle sharing systems with service level constraints. Transp. Res. E 2011, 47, 284-294. [CrossRef]

62. Tironi, M. (De)politicising and Ecologising Bicycles: The history of the Parisian Velib system and its controversies. J. Cult. Econ. 2015, 8, 1-18. [CrossRef]

63. Shaheen, S.; Guzman, S. Worldwide Bikesharing. Romania 2011, 1, 3.

64. Transport for London. Cycling. Available online: https://www.tfl.gov.uk/corporate/about-tfl/what-wedo/cycling (accessed on 1 July 2014).

65. Serco. Transport Case Study. Available online: http://www.serco.com/about/servicetolife/transportcasestudy. asp (accessed on 1 July 2014).

66. BBC. Barclays' $£ 25 m$ Sponsorship of London Cycle Hire Scheme. Available online: http://www.bbc.co.uk/ news/10182833 (accessed on 1 July 2014).

67. Whitehead, F. London Bike Hire Scheme on Road to Be Only Public Transport System in Profit. Available online: http:/ / www.theguardian.com/environment/green-living-blog/2010/oct/13/london-bike-hireprofit (accessed on 1 July 2014).

68. Department for Transport. Briefing on the Government's Ambition for Cycling; DfT: London, UK, 2013.

69. Mayor of London. The Mayor's Transport Strategy. Available online: https://www.london.gov.uk/sites/ default/files/mts_executive_summary.pdf (accessed on 9 February 2017).

70. Mayor of London. Mayor Sets Out Budget to Continue London's Green Revolution. Available online: http://london.gov.uk/media/mayor-press-releases/2008/01/mayor-sets-out-budget-to-continue-londonsgreen-revolution (accessed on 1 July 2014).

71. Meadowcroft, J. What about the politics? Sustainable development, transition management, and long term energy transitions. Policy Sci. 2009, 42, 323-340. [CrossRef]

72. Grin, J. The multi-level perspective and the design of system innovations. CRC Press 2008, 116, 119-127.

73. Angelo, H.; Wachsmuth, D. Urbanising Urban Political Ecology: A Critique of Methodological Cityism. Int. J. Urban Reg. Res. 2015, 39, 16-27. [CrossRef]

74. Peck, J.; Theodore, N.; Brenner, N. Neoliberal Urbanism Redux? Int. J. Urban Reg. Res. 2013, 37, 1091-1099. [CrossRef]

75. Peck, J. Austerity urbanism: American cities under extreme economy. City 2012, 16, 626-655. [CrossRef]

76. Amin, A. Telescopic Urbanism and the Poor. City 2013, 17, 476-492. [CrossRef]

77. McCann, E. Urban policy mobility and global circuits of knowledge: Towards a research agenda. Ann. Assoc. Am. Geogr. 2011, 101, 107-130. [CrossRef]

78. Eadson, W. State enrolment and energy-carbon transitions: Syndromic experimentation and atomisation in England. Environ. Plan. C 2016, in press. [CrossRef]

79. Berger, G.; Feindt, P.; Holden, E.; Rubik, F. Sustainable Mobility—Challenges for a Complex Transition. J. Environ. Policy Plan. 2014, 16, 303-320. [CrossRef]

80. Banister, D. The sustainable mobility paradigm. Transp. Policy 2008, 15, 73-80. [CrossRef]

81. Alexander, B.; Dijst, M.; Ettema, D. Working from 9 to 6? An analysis of in-home and out-of-home working schedules. Transportation 2010, 37, 505-523. [CrossRef]

82. Parkhurst, G.; Kemp, R.; Dijk, M.; Sherwin, H. Intermodal Personal Mobility: A Niche Caught between Two Regimes. In Automobility in Transition? A Socio-Technical Analysis of Sustainable Transport; Geels, F.W., Kemp, R., Dudley, G., Lyons, G., Eds.; Routledge: New York, NY, USA, 2012.

83. Newman, P.; Kenworthy, J. Cities and Automobile Dependence: An International Sourcebook; Gower: Aldershot, UK, 1989.

84. Wells, P.; Nieuwenhuis, P.; Orsato, R.J. The nature and causes of inertia in the automotive industry: Regime stability and non-change. In Automobility in Transition? A Socio-Technical Analysis of Sustainable Transport; Geels, F.W., Kemp, R., Dudley, G., Lyons, G., Eds.; Routledge: New York, NY, USA, 2012.

85. Office for National Statistics. Record Proportion of People in Employment Are Home Workers. Available online: http://www.ons.gov.uk/ons/rel/lmac/characteristics-of-home-workers/2014/sty-homeworkers.html (accessed on 2 November 2015). 
86. Haddad, H.; Lyons, G.; Chatterjee, K. An examination of determinants influencing the desire for and frequency of part-day and whole-day homeworking. J. Transp. Geogr. 2009, 17, 124-133. [CrossRef]

87. Neuman, M. The Compact City Fallacy. J. Plan. Educ. Res. 2005, 25, 11-26. [CrossRef]

88. Organisation for Economic Co-operation and Development. Compact City Policies: A Comparative Assessment; OECD: Paris, France, 2012.

89. Burton, E. The Compact City: Just or Just Compact? A Preliminary Analysis. Urban Stud. 2000, 37, $1969-2001$. [CrossRef]

90. Howley, P. Attitudes towards compact city living: Towards a greater understanding of residential behavior. Land Use Policy 2009, 26, 792-798. [CrossRef]

91. Gordon, I. Density and the built environment. Energy Policy 2008, 36, 4652-4656. [CrossRef]

92. Dieleman, F.; Dijst, M.; Spit, T. Planning the compact city: The randstad Holland experience. Eur. Plan. Stud. 1999, 7, 605-621. [CrossRef]

93. Westerink, J.; Haase, D.; Bauer, A.; Ravetz, J.; Jarrige, F.; Aalbers, C.B.E.M. Dealing with sustainability trade-offs of the compact city in peri-urban planning across European city regions. Eur. Plan. Stud. 2013, 21, 473-497. [CrossRef]

94. Smith, N. Uneven Development: Nature, Capital and the Production of Space; Verso: London, UK, 2010.

95. Cochrane, A. Exploring the regional politics of 'sustainability': Making up sustainable communities in the South-East of England. Environ. Policy Gov. 2010, 20, 270-381. [CrossRef]

96. Griffin, L. Editorial: Governance Innovation for Sustainability: Exploring the Tensions and Dilemmas. Environ. Policy Gov. 2010, 20, 365-369. [CrossRef]

97. Skelcher, C.; Sullivan, H.; Jeffares, S. Hybrid Governance in European Cities: Neighbourhood, Migration and Democracy; Palgrave-Macmillan: London, UK, 2013.

98. Bache, I.; Bartle, I.; Flinders, M.; Marsden, G. Blame Games and Climate Change: Accountability, Multi-Level Governance and Carbon Management. Br. J. Politics Int. Relat. 2015, 17, 64-88. [CrossRef]

99. Flint, J.; Raco, M. (Eds.) The Future of Sustainable Cities: Critical Reflections; Policy Press: Bristol, UK, 2012.

100. De Jong, M.; Joss, S.; Schraven, D.; Zhan, C.; Weijnen, M. Sustainable-smart-resilient-low-carbon-ecoknowledge cities; making sense of a multitude of concepts promoting sustainable urbanization. J. Clean. Prod. 2015, 109, 25-38. [CrossRef] 